\title{
Transposition effects in reading Japanese Kana: Are they orthographic in nature?
}

\author{
Manuel Perea - Chie Nakatani • Cees van Leeuwen
}

Published online: 9 December 2010

(C) Psychonomic Society, Inc. 2010

\begin{abstract}
One critical question for the front end of models of visual-word recognition and reading is whether the stage of letter position coding is purely orthographic or whether phonology is (to some degree) involved. To explore this issue, we conducted a silent reading experiment in Japanese Kana- a script in which orthography and phonology can be easily separated - using a technique that is highly sensitive to phonological effects (i.e., Rayner's (1975) boundary technique). Results showed shorter fixation times on the target word when the parafoveal preview was a transposed-mora nonword (a.ri.me.ka [アリメカ]-a.me.ri.ka [アメリカ]) than when the preview was a replacement-mora nonword (a.ka.ho. ka [アカホカ] -a.me.ri.ka [アメリカ]). More critically, fixation times on the target word were remarkably similar when the parafoveal preview was a transposed-consonant nonword (a.re.mi.ka [アレミカ]-a.ri.me.ka [アリメカ]) and when the parafoveal preview was an orthographic control nonword (a.ke.hi.ka [アケヒカ]-a.me.ri.ka [アメリカ]). Thus, these findings offer strong support for the view that letter/mora position coding during silent reading is orthographic in nature.
\end{abstract}

Keywords Masked priming · Visual-word recognition . Coding scheme

M. Perea $(\square)$

Departamento de Metodología, Facultad de Psicología,

Universitat de València,

Av. Blasco Ibáñez, 21,

46010 Valencia, Spain

e-mail: mperea@valencia.edu

C. Nakatani $\cdot$ C. van Leeuwen

Riken Institute,

Wako-shi, Japan
Across a variety of paradigms, a number of researchers have consistently found that transposed-letter nonwords (e.g., jugde) are very similar to their base words. For instance, using the masked priming paradigm, a target word is identified more rapidly when it is preceded by a transposed-letter nonword (e.g., jugde-JUDGE) than when it is preceded by an orthographic control (jupte-JUDGE) (see, e.g., Perea \& Lupker, 2003a, 2003b, 2004; see also Guerrera \& Forster, 2008; Schoonbaert \& Grainger, 2004). This "transposed-letter" phenomenon strongly suggests that the cognitive system employs a flexible coding for letter position (see SOLAR model, Davis, 1999, 2010; SERIOL model, Whitney, 2001; open bigram model, Grainger \& van Heuven, 2003; overlap model, Gomez, Ratcliff, \& Perea, 2008; noisy Bayesian reader model, Norris, Kinoshita, \& van Casteren, 2010, for instances of models that accommodate transposition effects).

One critical issue in the present study is whether the obtained transposition effects are orthographic in nature, or whether phonology is - to some degree - involved. All of the input coding schemes cited previously assume that the locus of transposition effects is at an early orthographic stage. However, none of these schemes has an implemented a phonological module in the first place. The empirical evidence regarding the role of phonology in transposition effects is scarce and restricted to just one laboratory word identification tasknamely, the lexical decision task. A number of masked priming lexical decision experiments by Perea and colleagues (e.g., Perea \& Carreiras, 2006, 2008; see also Acha \& Perea, 2010) failed to obtain any signs of an effect of phonology in letter position coding. However, it is very difficult to disentangle orthography and phonology in alphabetic languages, so the manipulation of phonology in the aforementioned experiments was a bit weak; that is, just one single letter/phoneme was changed (e.g., relobución-REVOLUCIÓN vs. reloduciónREVOLUCIÓN in the Perea \& Carreiras, 2006 experiments; 
note that the phoneme $/ \mathrm{b} /$ corresponds to the letters $\mathrm{v}$ and $\mathrm{b}$ in Spanish).

Another approach to look for evidence of phonological involvement in letter position coding is to manipulate the pronounceability of the transposed letters. In a lexical decision task, Frankish and Turner (2007) found that (briefly presented) nonwords created by swapping two letters were more wordlike (i.e., they produced more "word" responses) when these nonwords were unpronounceable (sotrm; i.e., via an illegal bigram) than when they were pronounceable (strom; via a legal bigram; see also Rumelhart, 1977, for a similar finding). Likewise, the magnitude of masked priming effects is greater when the transposed-letter primes form an illegal letter combination (e.g., sotrm-STORM) string than when they form a legal letter combination (e.g., strom-STORM; see Frankish \& Barnes, 2008; Perea \& Carreiras, 2008). However, as noted by Grainger (2008), these bigram effects could just be due to orthographic legality rather than to phonology.

A more powerful test of the role of phonology in transposition effects is to conduct the experiments in a language in which orthography and phonology can be readily separated. This was the rationale of the Perea and Pérez (2009) masked priming lexical decision experiments. Perea and Pérez employed a syllable-based script, Japanese Katakana, rather than an alphabetic script. Japanese language is written as a combination of three scripts: Kanji (i.e., logographic Chinese characters) and two syllabic scripts (i.e., Hiragana and Katakana), as in the sentence “悪徳業者にだまされて二セモノを買わされた”（see Sainio, Hyönä, Bingushi, \& Bertram, 2007, for eyetracking experiments using Japanese sentences). ${ }^{1}$ Hiragana and Katakana are syllabaries in which each character represents one syllable, or more specifically, a mora (see Delattre, 1966; Kinoshita, 1998). More importantly, two CV morae tend to be orthographically different even though they share the same consonant or the same vowel (e.g., れ in Hiragana corresponds to the mora $r e$, whereas $け$ corresponds to the mora $k e$ ). The basic distinction between Katakana and Hiragana is that Katakana is most often used for the transcription of words from foreign languages or for the transcription of words denoting foreign countries/places, whereas Hiragana words are frequently used for the expression of native Japanese words for which there is no Kanji. Hiragana is the script that is first taught to Japanese children and to learners of Japanese (e.g., many children's/ learners' books are written in Hiragana). At a perceptual level, Katakana morae have more straight lines than do Hiragana morae; for instance, the mora no corresponds to $の$ in Hiragana and to $ノ$ in Katakana.

\footnotetext{
${ }^{1}$ In this sentence, there is only one Katakana word: 二セモノ. The other words are written in Hiragana or in Kanji (the ideograms).
}

Perea and Pérez, (2009) found that the lexical decision times to a.me.ri.ka [アメリカ] were faster when the prime was the transposed-mora nonword a.ri.me.ka [アリメカ] than when the prime was the control nonword a.ka.ho.ka [アカホカ]. To determine whether this masked transposedmora effect was orthographic or phonological in origin, Perea and Pérez swapped two vowels/consonants in the internal morae (e.g., a.re.mi.ka [アレミカ]). There was no priming in this case (e.g., a.re.mi.ka [アレミカ]-a.me.ri.ka [アメリカ] similar to a.ke.hi.ka [アケヒカ]-a.me.ri.ka [ア メリカ]). Perea and Pérez concluded that masked transposed-mora effects were orthographic rather than phonological in nature. Note that Japanese readers are sensitive to submora effects at the phonological level. For instance, Tamaoka and Taft (1994) found that a nonword such as コメラ (ko.me.ra, the base word is カメラ, Japanese for camera) produced longer lexical decision times than did a nonword such as ソメラ (so.me.ra).

One potential problem in the previous studies on transpositions and phonology is that masked phonological priming tends to be very fragile in behavioral measures (Rastle \& Brysbaert, 2006). For instance, Carreiras, Perea, Vergara and Pollatsek (2009) found a significant masked phonological priming effect (e.g., conal-CANAL vs. cinal$C A N A L)$ when measuring the ERP waves, whereas the effect was not significant in the lexical decision times. Although experiments with standard laboratory tasks (e.g., lexical decision combined with masked priming) may offer valuable information on the early stages of visual-word processing, we believe that it is critical to examine whether orthographic/phonological information from the transposed-letter stimuli actually influences normal silent reading. To do that, one needs to run a silent reading experiment while the participants' eye movements are monitored. This is the approach we employed in the present experiment. We used Rayner's (1975); see also Rayner, 1998) boundary technique using target words in Kana script during normal reading (see Fig. 1 for a depiction of this technique). In this technique, the manipulation is the relation between a parafoveal preview-rather than a foveal prime - and a target word. In the sentence Most experienced runners stretch before and after a race, the target word could be stretch. The parafoveal preview could be a transposed-letter nonword such as strtech or a control nonword such as strboch. The parafoveal preview changes to stretch when the reader's eyes cross an invisible boundary just before the target word (see Fig. 1). The rationale here is that, although a given item is the parafovea, not only abstract letter codes are activated during silent reading, but also phonological codes (see Rayner, 1998, for a review).

Particularly relevant for the present experiment is the work by Pollatsek, Lesch, Morris, and Rayner (1992). 
Most experienced runners $\mid$ strtech both before and after a race.

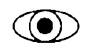

Most experienced runners stretch both before and after a race

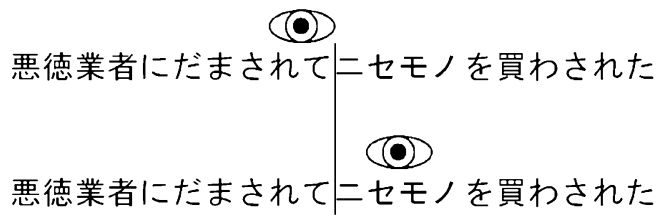

Fig. 1 Example sentences from a trial using the boundary technique. The eye icon represents the fixation point of a given reader in the sentence. Before the eyes cross the invisible boundary, the sentence is presented with the transposition nonword (see top line; e.g., strtech). Once the eyes cross the boundary, the text is replaced with the target word (see bottom line). The target words are stretch and 二セモノ in the English and Japanese sentences, respectively

Pollatsek and colleagues found that the fixation times on a target word (e.g., beach) were shorter when the parafoveal preview was a homophonic word (beech) than when it was a nonhomophonic control word (bench) (see also Chace, Rayner \& Well, 2005, Miellet \& Sparrow, 2004, and Tsai, Lee, Tzeng, Hung, \& Yen, 2004, for replications in English, French, and Chinese, respectively). These findings strongly suggest that readers employ phonological codes to integrate information across consecutive saccades. Importantly, phonological effects with the boundary technique have also been obtained under conditions of partial phonological overlap. Ashby and Rayner (2004) found a syllable congruency effect by manipulating the syllabic structure of the parafoveal previews: Fixation times on the target word device were shorter when the parafoveal preview was $d e \_\pi x w$ than when the preview was $d e v \_\pi x$ (see also Winskel, 2010, for evidence of tone congruency effects in Thai). Interestingly, the syllable congruency effects reported by Ashby and Rayner study were more robust when using parafoveal previews with the boundary technique (i.e., the technique employed in the present experiment) than when using a "fast priming" technique in which the primes were presented foveally.

Prior studies have reported robust transposed-letter effects in the parafovea with the boundary technique (Johnson, 2007; Johnson, Perea, \& Rayner, 2007). Indeed, silent reading experiments using the boundary technique seem to be highly sensitive to transposed-letter effects. Johnson et al. (Experiment 1) found that fixation times on a target word (e.g., judge) were shorter when the parafoveal preview was an adjacent transposed-letter nonword than when the parafoveal preview was an orthographic control nonword: The magnitude of the effect was similar in size for internal transpositions (e.g., jugde-judge vs. jupte-judge) and for final transpositions (judge-judge vs. judop-judge). Likewise, Johnson obtained a transposedletter effect when the parafoveal nonwords had been created by transposing nonadjacent letter positions (e.g., canisocasino faster than caviro-casino). Thus, the experiments of Johnson and colleagues clearly demonstrate that: (a) letter information can be attained in the parafovea during normal silent reading, and (b) letter position is highly flexible in the parafovea during normal silent reading. In other words, transposed-letter effects are not restricted to laboratory word identifications tasks. However, orthography and phonology were confounded in the Johnson et al. experiments and, as a result, these experiments do not inform us of the potential differing role of orthography versus phonology during silent normal reading.

In the present study, we examined the role of orthography/phonology in transposition effects using Rayner's boundary technique in normal silent reading. We employed a highly transparent script (Japanese Hiragana and Katakana) that allowed us to separate orthography and phonology. Japanese has two potential writing formats (from top to bottom; from left to right). We chose the horizontal format, as in Western languages. The first goal of the study was to examine whether it was possible to obtain a parafoveal benefit with the transposition of two internal morae in Japanese Hiragana and Katakana (e.g., a.ri.me.ka-a.me.ri.ka [アリメカ - ア メリカ]) relative to the appropriate control (a doublesubstitution condition, e.g., a.ka.ho.ka-a.me.ri.ka [アカホ カーアメリカ]). Note that the Perea and Pérez (2009) experiments only employed Katakana stimuli. Given that the Katakana script is mostly used for foreign words, we believe that it is important to study whether transposedmora effects can also be obtained with the more common Hiragana script. If the underlying mechanisms of letter position coding and mora position coding are akin, then a parafoveal preview benefit from transposed stimuli should exist in a syllabic script (both in Hiragana and Katakana), as occurs in the Roman script (Johnson, 2007; Johnson et al., 2007).

The second goal of the study was to test the role of phonology in mora position coding. We did so by transposing two consonants in the internal mora (e.g., a.re. mi.ka-a.me.ri.ka [アレミカーアメリカ]) versus the orthographic control a.ke.hi.ka-a.me.ri.ka, [アケヒカ -アメリ カ]). We manipulated consonants rather than vowels because consonants seem to play a greater role than vowels in lexical access (see Carreiras, Gillon-Dowens, Vergara \& Perea, 2009). If fixation times on the target word a.me.ri.ka are shorter when the parafoveal preview is the transposedphoneme nonword a.re.mi.ka than when the preview is the control nonword a.ke.hi.ka, this would imply that phonological information is influencing mora position encoding 
during normal silent reading. If that is the case, the front end of the models of visual-word recognition (e.g., overlap model, Gómez et al., 2008; open-bigram model, Grainger \& van Heuven, 2003; SOLAR model, Davis, 2010; noisy Bayesian reader model, Norris et al., 2010; SERIOL model, Whitney, 2001) should be modified to accommodate this phenomenon. Alternatively, if fixation times on the target word amerika are similar when the parafoveal preview is a. re.mi.ka and when the parafoveal preview is a.ke.hi.ka, the front end of these models wouldn't need to be modified.

\section{Method}

\section{Participants}

Twenty-four university students and volunteers at the RIKEN Institute participated in the experiment. Those who participated from outside of the RIKEN Institute received monetary compensation (1,000 JPY/hour) for their time. All participants had normal vision or soft contacts and were native speakers of Japanese. They were all naive to the purpose of the experiment.

\section{Apparatus}

Participants were seated in front of a 21-in. color monitor (VX1120, Gateway Japan, Tokyo, Japan) in which singleline sentences were presented at a refresh rate of $80 \mathrm{~Hz}$. The observers' heads were fixed with chin- and forehead rests. The distance between the participants' eyes and the display was $85 \mathrm{~cm}$. At this distance, four morae in MS-Mincho (equi-width) font equaled $1.62^{\circ}$ of visual angle. Eye movements were recorded using an SMI Eyelink 1000 System (EyeLink 1000/Tower, SR Research Ltd., Ontario, Canada) interfaced with a Windows-based computer. This eyetracker has a spatial resolution of $10 \mathrm{~min}$ of arc. Reading took place binocularly, but the eyetracker only recorded data from the participant's right eye. Eye position was sampled every millisecond.

\section{Stimuli}

The target stimuli were 44 Hiragana words and 44 Katakana words of four morae length. Written-word frequencies, per million words, in the NTT Japanese database (Amano \& Kondo, 2000) were 10.6 and 6.3 for the Hiragana and Katakana words, respectively. (Six Hiragana words and six Katakana words did not appear in the Amano and Kondo (2000) list.) In all cases, the two internal morae always had a phonological CV structure, and none of the constituent phonemes of the internal morae was repeated. These stimuli were used as target words and set in into a single-line sentence. Target words never occupied the initial or final position. Four nonword parafoveal previews were created for each target word. In the transposed-mora condition, the preview involved the transposition of the two internal morae (ひらぐし [hi.ra.gu.shi] as the preview of ひぐらし [hi.gu. ra.shi]). The replacement-mora condition involved the substitution of the two internal morae so that the resulting nonword preview did not share any phonemes in common with the internal morae of the base word (ひでびし [hi.de.bi.shi] as the preview of ひぐらし [hi.gu.ra.shi]). The transposedphoneme condition involved the replacements of the two internal morae so that the consonant sounds of these morae did not vary, whereas the vowel sounds were switched across the two internal morae (ひるがし [hi.ru.ga.shi] as the preview of ひぐらし [hi.gu.ra.shi]). The control transposed-phoneme condition involved the substitution of the two internal morae so that the consonant sounds of these morae were replaced, whereas the vowel sounds did not vary (e.g., ひくなし [hi. ku.na.shi] as the preview of ひぐらし [hi.gu.ra.shi]). The (token) frequency of the critical (manipulated) morae was matched across the prime conditions using the Tamaoka and Makioka (2004) mora frequency count for four-mora words. None of the experimental words was a compound. The sentences and preview conditions are available at http://www. uv.es/mperea/Perea_Nakatani_VanLeeuwen.pdf. We created four counterbalancing lists in a Latin-square design (i.e., every participant read 24 sentences in each of the four preview conditions).

\section{Procedure}

Participants were tested individually in a quiet room. They were asked to read for comprehension, as they normally read. They were instructed to press a button on a response box when they finished reading each sentence. To familiarize the participants with the procedure, a practice phase consisting of 12 sentences was presented once, concluding the initial calibration. On each trial, participant had to fixate on the first letter of the first word in the sentence. We followed the standard procedure of the boundary paradigm (Rayner, 1975) (see Fig. 1 for an example). That is, once the participant's eyes crossed an invisible boundary just to the left of the target word, the parafoveal preview changed to the target word. This display change occurred while the participant's eyes were moving, and participants did not usually notice any display change. ${ }^{2}$ Then, the target word was present until the participant indicated that he or she was finished reading the sentence. Recalibration was

\footnotetext{
${ }^{2}$ When asked after the experiments, four participants reported having noticed some flickering and that, occasionally, they were able to detect a few display changes. The pattern of data was exactly the same if we excluded these four participants from the data analysis.
} 
performed before each trial whenever it was necessary for accuracy purposes. No mention was made of the display changes in the instructions. The sentences were presented in a random order for each participant. To make sure that participants were actually reading, comprehension questions were presented after $15 \%$ of the trials. In this case, participants were instructed to respond a two-alternative choice question by pressing the corresponding button on their response boxes. Comprehension scores in the experiment had a mean of $96 \%$ (range: $80-100 \%$ ). The entire experiment took less than $45 \mathrm{~min}$.

Data analysis

As in previous parafoveal preview experiments (e.g., Johnson et al., 2007), we focused on the mean first-fixation duration (i.e., the duration of the first-pass initial-fixation duration on the target word), single-fixation duration (i.e., the duration of the fixation when the reader, on the first pass, made one and only one fixation on the target word), and gaze duration (i.e., the sum of fixation durations on a target word, on the first pass, before the reader's gaze left the word). Note that firstfixation durations and single-fixation durations reflect very early word recognition processes, whereas gaze durations may reflect slightly later effects because they include the potential refixations on the target word (see, e.g., Ashby \& Rayner, 2004).

\section{Normative data}

As usual, we collected normative data on the predictability and understability of the target word in the sentences. First, we prepared a questionnaire in which the initial part of each sentence - up to the target word-was presented to 11 university students. They were asked to predict the following word. Less than $1 \%$ of the words were predicted from the prior context. Second, another sample of 11 university students judged how understandable the target word was in each sentence on a scale from 1 (not understandable) to 7 (very understandable). The average score was quite elevated (6.5). None of these individuals took part in the eyetracking experiment.

\section{Results}

Sentences in which the eyetracker lost track of the eye, the display change triggered too early/late, or when the participant blinked on the target word (or on the preceding/following word) were discarded from the analyses. Likewise, trials in which there were two fixations on contiguous letters and one of the fixations was very brief (less than $120 \mathrm{~ms}$ ) were merged. Finally, extremely brief (less than $120 \mathrm{~ms}$ ) isolated fixations and extremely long (greater than $800 \mathrm{~ms}$ ) fixations were removed from the data. In total, $14 \%$ of the data was eliminated. The mean firstfixation duration, single fixation duration, and gaze duration for each of the parafoveal preview conditions are shown in Table 1. As in the Perea and Pérez (2009) study, we examined separately the presence of mora transposition effects and the presence of phonological transposition effects. To test for mora transposition effects, ANOVAs based on the participant and item average fixation times were conducted using a 2 (type of prime: transposition, double substitution) x 4 (list: List 1, List 2, List 3, List 4) design. In addition, to test for phonological transposition effects, ANOVAs based on the participant and item average fixation times were conducted using a 2 (prime type: phoneme transposition, phoneme replacement) $\mathrm{x} 4$ (ist: List 1, List 2, List 3, List 4) design. List was included in the analyses as a dummy factor to extract the error variance due to the lists (Pollatsek \& Well, 1995). All significant effects had $p$ values less than .05 .

\section{Transposition mora effects}

Fixation times on the target word were shorter when the preview involved the transposition of internal morae than
Table 1 Means as a function of type of preview and script for the experiment

All durations for first fixation, single fixation, and gaze are in milliseconds

\begin{tabular}{llll}
\hline & First Fixation & Single Fixation & Gaze Duration \\
\hline Hiragana & 303 & & 365 \\
Transposition & 339 & 301 & 426 \\
Control transposition & 326 & 342 & 415 \\
Phonological & 328 & 347 & 428 \\
Control phonological & & 356 & \\
Katakana & 279 & & 336 \\
Transposition & 326 & 278 & 410 \\
Control transposition & 319 & 351 & 427 \\
Phonological & 319 & 348 & 424 \\
Control phonological & & 335 & \\
\hline
\end{tabular}


when the preview involved the substitution of the internal morae: The effect size was $41 \mathrm{~ms}$ for first-fixation duration, $F 1(1,20)=25.81, M S E=1,626 ; F 2(1,80)=39.61$, $M S E=1,732,51 \mathrm{~ms}$ for single-fixation duration, $F 1(1,20)=$ $7.44, M S E=1,162 ; F 2(1,80)=20.51, M S E=6,263$, and $67 \mathrm{~ms}$ for gaze duration, $F 1(1,20)=37.74, M S E=2,947$; $F 2(1,80)=31.11, M S E=5,360$. This transposed-mora effect was similar in size for Hiragana and Katakana words, as deduced by the lack of interaction between script and transposition (all $F_{\mathrm{S}}<1.1$ ). Finally, the main effect of script was significant on single-fixation durations, $F 1(1,20)=$ $7.44, M S E=1,162 ; F 2(1,80)=7.62, M S E=2,424$, and on gaze duration, $F 1(1,20)=4.71, M S E=2,572 ; F 2(1,80)=$ $4.38, M S E=8,537$, reflecting shorter fixation durations on Hiragana than on Katakana words.

\section{Phonological transposition effects}

There were no trends of a phonological transposition effect in the first-fixation durations, single-fixation durations, or gaze durations (all $F_{\mathrm{S}}<1$ for the main effect of phonological transposition and for the two-way interaction with script) (see Table 1). We should note that we conducted some post hoc analyses including launch site as a factor; we failed to obtain any consistent pattern regarding phonological transposition effects in the parafovea for both distant and close launch sites (all $F \mathrm{~s}<1$ ).

\section{Discussion}

This is the first experiment that has examined the role of phonology in transposition effects during silent reading; previous research employed laboratory word identification tasks. Furthermore, we did so in a language (Japanese Kana) in which phonology and orthography can be elegantly separated. The results are straightforward: Fixation times on a target Kana word were shorter when the parafoveal preview was a transposed-mora nonword (e.g., a.ri.me.ka-a.me.ri.ka [アリメカ - アメリカ]) than when it was a replacement-mora nonword (a.ka.ho.ka-a.me.ri.ka [アカホカ - アメリカ). The locus of this effect was at the orthographic level because we found remarkably similar fixation times when the parafoveal preview was a transposed-phoneme nonword (e.g., a.re.mi.ka-a.me.ri.ka [アレミカーアメリカ]) and when the parafoveal preview was an orthographic control (a.ke.hi.ka-a.me.ri.ka [アケヒ カーアメリカ]). Finally, the pattern of data was remarkably similar in Hiragana and in Katakana scripts.

The presence of the transposed-mora effect with parafoveal previews extends prior research of Perea and Pérez, (2009) with Katakana words in a lexical decision task, this time using a more ecologically valid task and the two Kana scripts (Katakana and Hiragana). Thus, models of letter position encoding should be expanded to take into account not only letters (in alphabetic systems) but also morae (in syllabic scripts). For instance, in the overlap model (Gómez et al., 2008), the locations of morae (or of any other "objects") would be considered as distributions along a dimension rather than as exact points (i.e., there would be some position uncertainty associated with the position of each mora; see Perea \& Pérez, 2009, on how other input coding schemes can be expanded to Kana morae).

Importantly, one can sensibly think that mora position coding in the case of Japanese Kana is quite flexible, as is actually the case. Bear in mind that Japanese is written without spaces (see Fig. 1, or see the Appendix http://www. uv.es/mperea/Perea_Nakatani_VanLeeuwen.pdf with the materials), so there is some amount of uncertainty in relation to which word a given mora belongs toparticularly when there are two or more Kana words in a row. That is, the word-processing system needs to determine not just the position of the more within a word, but also the appropriate word to which the mora belongs. Thus, it is not surprising that the size of the obtained transposition effects in the present experiment - with standard unspaced text - is somewhat greater than the size of the transposedletter effects reported by Johnson et al., (2007) in English. ${ }^{3}$ Thus, the present data suggest that the stage of letter/mora position coding is - to some degree-language independent. We acknowledge, however, that factors such as visual format (as Korean Hangul; see Lee \& Taft, 2009) or the morphological characteristics of a given language (e.g., the ordering of the root letters in Semitic languages; Velan \& Frost, 2009; see also Perea, Abu Mallouh, \& Carreiras, 2010; Perea, Abu Mallouh, García-Orza \& Carreiras, 2010) may influence the process of letter position coding.

The failure to obtain a transposed-phoneme parafoveal preview benefit in Japanese Kana is consistent with the experiments of Perea and colleagues in alphabetic languages (Perea \& Carreiras, 2006, 2008; see also Acha \& Perea, 2010). Thus, the locus of transposition effects seems to be quite early - that is, before phonological influences occur. The present data are also consistent with a recent lexical decision experiment by Bowers, (2008), in which transposedletters nonwords (e.g., cholocate) produced longer response times and more errors than did replacement-letter nonwords when presented visually; however, when these same nonwords were presented auditorily, there were no signs of a transposition effect. Similarly, using event related potentials,

\footnotetext{
${ }^{3}$ In the present experiment, we did not include an identity preview condition as an additional baseline. The reason is that it is difficult to compare a transposition condition and an identity condition because there is no display change in the case of an identity parafoveal preview.
} 
Grainger, Kiyonaga, and Holcomb, (2006) found that masked transposed-letter priming (barin-BRAIN vs. bosin$B R A I N$ ) occurs earlier (and with a different topographical distribution) than masked pseudohomophone priming (brane-BRAIN vs. brant-BRAIN). As was indicated in the introduction, all these data (including those in the present experiment) are entirely consistent with the orthographic coding schemes of models of visual word recognition (i.e., the front end of the models is not shaped by phonology).

Therefore, the present experiment offers further strong empirical support for the view that letter/mora position coding occurs at a very early orthographic stage that is unaffected by phonology: The experiment employed a highly ecological task (i.e., monitoring the readers' eye movements during silent reading) in a script (Japanese Kana) in which orthography and phonology could be easily disentangled. Furthermore, we must keep in mind that, during normal silent reading, phonological codes are used to integrate information across consecutive saccades (see Chace et al., 2005; Miellet \& Sparrow, 2004; Pollatsek et al., 1992; Tsai et al., 2004). One might wonder, however, whether there is a high degree of phonological involvement in reading Japanese sentences. For instance, Kinoshita (1998) indicated that the role of phonology in Japanese might be less critical than it is in English. In this respect, we should note that, in the present experiment, firstfixation durations for target words preceded by a doublereplacement preview (ひでびし[hi.de.bi.shi] as the preview of ひぐらし [hi.gu.ra.shi]) were $9 \mathrm{~ms}$ slower than those for the phonological control condition (e.g., ひくなし[hi.ku.na. shi] as the preview of ひぐらし [hi.gu.ra.shi]). This difference approached significance in the analysis by items, $F 2(1,80)=2.82, M S E=1,738, p=.09 ; F 1(1,20)=2.48$, $M S E=2,394, p=.12$. Thus, even though the aforementioned test did not reach the classical level for significance, it does suggest that it is possible to obtain phonological effects in Japanese at the phoneme level using parafoveal previews, even with a rather subtle manipulation. Furthermore, this effect is numerically similar to the phonological effects with partial overlaps reported in the literature on eye movements and reading: Ashby and Rayner, (2004) found a 13-ms effect of syllable congruency in first-fixation durations in English, and Winskel, (2010) reported a 14-ms effect of tone congruency in first-fixation durations in Thai. Nonetheless, the critical point here is that although there were no hints of a phonological effect related to phoneme transpositions (e.g., hi.ra.gu.shi-hi-gu.ra.shi and hi.de.bi.shi-hi.gu.ra.shi produced very similar fixation times; all $F_{\mathrm{S}}<1$ ), a subtle phonological manipulation (hi.ku.na.shi-hi.gu.ra.shi faster than hi.de.bi. shi-hi.gu.ra.shi) produced effects similar to those reported in the literature on partial phonological overlap. Taken together, these findings strongly suggest that letter/mora position coding during the early stages of visual-word recognition is orthographic, rather than phonological, in nature.
In sum, mora transpositions effects are fairly robust during normal silent reading in Japanese. Similar to alphabetic languages (see Johnson et al., 2007, for evidence in English), the word-processing system extracts mora identity information from the parafovea and uses it to aid the encoding of the subsequent words. Importantly, there are no signs of a transposition effect when phonology is manipulated, even in a procedure that is highly sensitive to phonological effects during normal silent reading (i.e., Rayner's boundary technique). Thus, the available empirical evidence supports the view that letter/mora position coding takes place before phonological information begins to matter.

\section{References}

Acha, J., \& Perea, M. (2010). Does kaniso activate CASINO? Input coding schemes and phonology in visual-word recognition. Experimental Psychology, 57, 245-251. doi:10.1027/1618-3169/ a000029.

Amano, N., \& Kondo, H. (2000). Nihongo no Goi Tokusei [Lexical characteristics of Japanese language]. NTT database series (Dai 2 ki; 7 kan, CD-Rom version). Tokyo: Sanseido

Ashby, J., \& Rayner, K. (2004). Representing syllable information during silent reading: Evidence from eye movements. Language and Cognitive Processes, 19, 391-426. doi:10.1080/ 01690960344000233

Bowers, J. (2008). Comparing letter and phoneme coding schemes for written and spoken word. Chicago, IL: Paper presented at the Pre-Psychonomics Lexical Processing conference.

Carreiras, M., Gillon-Dowens, M., Vergara, M., \& Perea, M. (2009). Are vowels and consonants processed differently? ERP evidence with a delayed letter paradigm. Journal of Cognitive Neuroscience, 21, 275-288. doi:10.1162/jocn.2008.21023

Carreiras, M., Perea, M., Vergara, M., \& Pollatsek, A. (2009). The time course of orthography and phonology: ERP correlates of masked priming effects in Spanish. Psychophysiology, 46, 11131122. doi:10.1111/j.1469-8986.2009.00844.x

Chace, K. H., Rayner, K., \& Well, A. D. (2005). Eye movements and phonological preview benefit: Effects of reading skill. Canadian Journal of Experimental Psychology, 59, 209-217. doi:10.1037/ h0087476

Davis, C. J. (1999). The self-organising lexical acquisition and recognition (SOLAR) model of visual word recognition (Doctoral dissertation, Royal Holloway University of London). Retrieved from http://www.pc.rhul.ac.uk/staff/c.davis/Thesis/ thesis.zip

Davis, C. J. (2010). The spatial coding model of visual word identification. Psychological Review, 117, 713-758. doi:10.1037/ a0019738

Delattre, P. (1966). A comparison of syllable length conditioning among language. International Review of Applied Linguistics, 4, 183-198. doi:10.1515/iral.1966.4.1-4.183

Frankish, C., \& Barnes, L. (2008). Lexical and sublexical processes in the perception of transposed-letter anagrams. Quarterly Journal of Experimental Psychology, 61, 381-391.

Frankish, C., \& Turner, E. (2007). SIHGT and SUNOD: The role of orthography and phonology in the perception of transposed letter anagrams. Journal of Memory and Language, 56, 189211. 
Gómez, P., Ratcliff, R., \& Perea, M. (2008). The overlap model: A model of letter position coding. Psychological Review, 115, 577601. doi:10.1037/a0012667

Grainger, J., \& van Heuven, W. J. B. (2003). Modeling letter position coding in printed word perception. In P. Bonin (Ed.), Mental lexicon: Some words to talk about words (pp. 1-23). Hauppauge, NY: Nova Science.

Grainger, J., Kiyonaga, K., \& Holcomb, P. J. (2006). The time course of orthographic and phonological code activation. Psychological Science, 17, 1021-1026. doi:10.1111/j.14679280.2006.01821.x

Grainger, J. (2008). Cracking the orthographic code: An introduction. Language and Cognitive Processes, 23(1), 1-135.

Guerrera, C., \& Forster, K. (2008). Masked form priming with extreme transposition. Language and Cognitive Processes, 23, 117-142. doi:10.1080/01690960701579722

Johnson, R. L. (2007). The flexibility of letter coding: Nonadjacent letter transposition effects in the parafovea. In R. van Gompel, M. Fisher, W. Murray, \& R. L. Hill (Eds.), Eye movements: A window on mind and brain (pp. 425-440). Oxford: Elsevier.

Johnson, R. L., Perea, M., \& Rayner, K. (2007). Transposed-letter effects in reading: Evidence from eye movements and parafoveal preview. Journal of Experimental Psychology: Human Perception and Performance, 33, 209-229.

Kinoshita, S. (1998). The role of phonology in reading Japanese: Or why I don't hear myself when reading Japanese. Reading and Writing, 10, 439-455.

Lee, C. H., \& Taft, M. (2009). Are onsets and codas important in processing letter position? A comparison of TL effects in English and Korean. Journal of Memory and Language, 60, 530-542.

Miellet, S., \& Sparrow, L. (2004). Phonological codes are assembled before word fixation: Evidence from boundary paradigm in sentence reading. Brain \& Language, 90, 299-310.

Norris, D., Kinoshita, S., \& van Casteren, M. (2010). A stimulus sampling theory of letter identity and order. Journal of Memory and Language, 62, 254-271. doi:10.1016/j.jml.2009.11.002

Perea, M., \& Lupker, S. J. (2003a). Does jugde activate COURT? Transposed-letter similarity effects in masked associative priming. Memory and Cognition, 31, 829-841.

Perea, M., \& Lupker, S. J. (2003b). Transposed-letter confusability effects in masked form priming. In S. Kinoshita \& S. J. Lupker (Eds.), Masked priming: State of the art (pp. 97-120). Hove, England: Psychology Press.

Perea, M., \& Lupker, S. J. (2004). Can CANISO activate CASINO? Transposed-letter similarity effects with nonadjacent letter positions. Journal of Memory and Language, 51, 231-246. doi:10.1016/j.jml.2004.05.005

Perea, M., \& Carreiras, M. (2006). Do transposed-letter similarity effects occur at a prelexical phonological level? Quarterly Journal of Experimental Psychology, 59, 1600-1613.

Perea, M., \& Carreiras, M. (2008). Do orthotactics and phonology constrain the transposed-letter effect? Language and Cognitive Processes, 23, 69-92. doi:10.1080/01690960701578146

Perea, M., \& Pérez, E. (2009). Beyond alphabetic orthographies: The role of form and phonology in transposition effects in Katakana. Language and Cognitive Processes, 24, 67-88. doi:10.1080/ 01690960802053924

Perea, M., Abu Mallouh, R., \& Carreiras, M. (2010). The search of an input coding scheme: Transposed-letter priming in Arabic. Psychonomic Bulletin and Review, 17, 375-380. doi:10.3758/ PBR.17.3.375
Perea, M., Abu Mallouh, R., García-Orza, J., \& Carreiras, M. (2010). Masked priming effects are modulated by expertise in the script. Quarterly Journal of Experimental Psychology. doi:10.1080/ 17470218.2010.512088

Pollatsek, A., Lesch, M., Morris, R. M., \& Rayner, K. (1992). Phonological codes are used in integrating information across saccades in word identification and reading. Journal of Experimental Psychology: Human Perception and Performance, 18, $148-162$.

Pollatsek, A., \& Well, A. D. (1995). On the use of counterbalanced designs in cognitive research: A suggestion for a better and more powerful analysis. Journal of Experimental Psychology: Learning, Memory, \& Cognition, 21, 785-794. doi:10.1037/ 0278-7393.21.3.785

Rayner, K. (1975). The perceptual span and peripheral cues in reading. Cognitive Psychology, 7, 65-81. doi:10.1016/00100285(75)90005-5

Rayner, K. (1998). Eye movements in reading and information processing: Twenty years of research. Psychological Bulletin, 124, 372-422. doi:10.1037/0033-2909.124.3.372

Rastle, K., \& Brysbaert, M. (2006). Masked phonological priming effects in English: Are they real? Do they matter? Cognitive Psychology, 53, 97-145.

Rumelhart, D. E. (1977). Toward an interactive model of reading. In S. Dornic (Ed.), Attention and performance VI (pp. 573-603). Hillsdale, NJ: Erlbaum.

Sainio, M., Hyönä, J., Bingushi, K., \& Bertram, B. (2007). The role of interword spacing in reading Japanese: An eye movement study. Vision Research, 20, 2575-2584.

Schoonbaert, S., \& Grainger, J. (2004). Letter position coding in printed word perception: Effects of repeated and transposed letters. Language and Cognitive Processes, 19, 333-367.

Tamaoka, K., \& Taft, M. (1994). Is the smallest unit in phonological processing equivalent to the smallest unit in orthographic processing?: Lexical judgements of Katakana non-words. Shinrigaku Kenkyu, 65, 377-382.

Tamaoka, K., \& Makioka, S. (2004). Frequency of occurrence for units of phonemes, morae, and syllables appearing in a lexical corpus of a Japanese newspaper. Behavior Research Methods, Instruments, \& Computers, 36, 531-547.

Tsai, J.-L., Lee, C.-Y., Tzeng, O. J.-L., Hung, D. L., \& Yen, N.-S. (2004). Use of phonological codes for Chinese characters: Evidence from processing of parafoveal preview when reading sentences. Brain and Language, 91, 235-244.

Velan, H., \& Frost, R. (2009). Letter-transposition effects are not universal: The impact of transposing letters in Hebrew. Journal of Memory and Language, 61, 285-302. doi:10.1016/j. jml.2009.05.003

Whitney, C. (2001). How the brain encodes the order of letters in a printed word: The SERIOL model and selective literature review. Psychonomic Bulletin and Review, 8, 221-243.

Winskel, H. (2010). Orthographic and phonological parafoveal processing of consonants, vowels, and tones when reading Thai. Applied Psycholinguistics.

The research reported in this article has been supported by Grant PSI2008-04069/PSIC from the Spanish Ministry of Science and Innovation, Spain. We thank two anonymous reviewers for their useful comments on an earlier version of the manuscript. 